\title{
The same clinical effect, with fewer complications and higher patient comfort, can be achieved with lower doses of N-butyl cyanoacrylate in endovenous ablation therapy: A prospective, randomized study
}

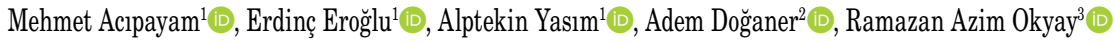 \\ ${ }^{1}$ Department of Cardiovascular Surgery, Kahramanmaraş Sütçü Imam University Faculty of Medicine, Kahramanmaraş, Turkey \\ ${ }^{2}$ Department of Biostatistics, Kahramanmaraş Sütçü Imam University Faculty of Medicine, Kahramanmaraş, Turkey \\ ${ }^{3}$ Department of Public Health, Kahramanmaraş Sütçü Imam University Faculty of Medicine, Kahramanmaraş, Turkey
}

\begin{abstract}
Objectives: This study aims to investigate the therapeutic effect of N-butyl cyanoacrylate (NBCA) administration on the treatment success and patient comfort in patients with venous insufficiency.

Patients and methods: Between March 2019 and June 2019, a total of 80 patients (29 males, 51 females; mean age $49.6 \pm 12.0$ years; range, 25 to 81 years) diagnosed with great saphenous vein incompetence and underwent endovenous ablation with $<1 \mathrm{~mL}$ or $>1.5 \mathrm{mLNBCA}$ were included in this prospective, randomized study. The patients were equally divided into two groups as Group 1 ( $\mathrm{n}=40$ ) receiving $<1 \mathrm{~mL} \mathrm{NBCA}$ and Group $2(\mathrm{n}=40)$ receiving $>1.5 \mathrm{~mL} \mathrm{NBCA}$. The patients were invited for checks on the third day and first month post-procedurally and were evaluated in terms of potential complications. Post-procedural analgesic requirements, time to first analgesic requirement, number of $500 \mathrm{mg}$ paracetamol doses used over three days among patients requiring analgesia, and pain experienced using the Visual Analog Scale after the procedure and on the third day were recorded.

Results: The mean lengths of vein segments subjected to NBCA application and ablation were $33 \mathrm{~cm}$ in Group 1 and $34 \mathrm{~cm}$ in Group 2 $(\mathrm{p}=0.430)$. Fewer adverse events were observed in Group 1 than Group 2 (phlebitis, $p=0.305$; ecchymosis, $p=0.396$; analgesic use, $p=0.013$; amount of analgesic used, $\mathrm{p}<0.001$; time to first analgesia requirement, $\mathrm{p}<0.001$ ).

Conclusion: Our study results suggest that the same clinical success with fewer complications (ecchymosis, phlebitis, and pain) and greater patient satisfaction can be achieved using a lower dose of NBCA in the treatment of venous insufficiency.

Keywords: Endovenous ablation, N-butyl cyanoacrylate, venous insufficiency.

Varicose vein treatment has evolved dramatically in recent years. Endovascular procedures, including radiofrequency ablation (RFA) and endovenous laser ablation (EVLA), employ thermal energy for vein wall modification and occlusion. The saphenous space must be infiltrated with tumescent anesthesia to reduce complications such as skin burns, lower extremity pain, skin pigmentation, and nerve damage and to enhance venous obliteration. ${ }^{[1]}$

Non-thermal non-tumescent (NTNT) techniques are available options for avoiding such complications

associated with great saphenous vein (GSV) and small saphenous vein (SSV) ablation. ${ }^{[2]}$ Tumescent anesthesia is not required with these techniques, since the vein is occluded either by mechanochemical energy, or else by sealing through adhesive action. When injected via the intravascular route, the N-butyl cyanoacrylate (NBCA) quickly solidifies as a result of a polymerization reaction, leading to an inflammatory reaction in the vein wall. ${ }^{[3-5]}$ Non-thermal ablation entails a number of potential advantages in terms of patient acceptability and a lower nerve injury risk. ${ }^{[6]}$
\end{abstract}

Received: April 28, 2020 Accepted: May 02, 2020 Published online: June 16, 2020

Correspondence: Mehmet Acıpayam, MD. Kahramanmaraş Sütçü İmam Üniversitesi Tıp Fakültesi Kalp ve Damar Cerrahisi Anabilim Dalı, 46000 Onikişubat, Kahramanmaraş, Türkiye. e-mail: mehmetacipayam@gmail.com 
Clinical studies and reviews have recently confirmed the safety, feasibility, and mid-term efficacy of NBCA. ${ }^{[2,7-9]}$ However, although uncommon, complications associated with the NBCA use such as phlebitis and ecchymosis can be still encountered. These complications mainly depend on the amount of the chemical substance applied. In the present study, we hypothesized that successful chemical ablation could be possible using a low level of NBCA and that the patient comfort could be increased by reducing the severity of inflammation in the vessel wall. We, therefore, aimed to investigate the effect of NBCA administration on early therapeutic success and patient comfort in patients with venous insufficiency.

\section{PATIENTS AND METHODS}

This prospective, randomized study was conducted at Kahramanmaras Sutcu Imam University, Faculty of Medicine, Department of Cardiovascular Surgery between March 2019 and June 2019. A total of 80 patients $(29$ males, 51 females; mean age $49.6 \pm 12.0$ years; range, 25 to 81 years) with GSV incompetence as assessed by Duplex ultrasound (DUS) and underwent endovenous ablation were included in the study. Patients with a GSV greater than $5.5 \mathrm{~mm}$ in diameter, $2 \mathrm{~cm}$ below the saphenofemoral junctions with the subject in a standing position, combined with reflux exceeding $0.5 \mathrm{sec}$, according to the European
Society of Vascular Surgery (ESVS) guidelines ${ }^{[10]}$ were to be eligible. Those aged less than 18 years, having deep venous system obstruction, a previous history of another invasive technique (i.e., thermal and chemical ablation, or surgery), cardiac and renal failure, those who were immobile or with secondary varicose veins, having hypercoagulability status, and local or systemic infection were excluded. A written informed consent was obtained from each patient. The study protocol was approved by the Ethics Committee of the Kahramanmaras Sutcu Imam University, Faculty of Medicine. The study was conducted in accordance with the principles of the Declaration of Helsinki.

Block randomization was performed using the sealed envelope method at a ratio of 1:1. The patients were equally divided into two groups as Group $1(\mathrm{n}=40)$ receiving $<1 \mathrm{~mL}$ NBCA and Group 2 $(\mathrm{n}=40)$ receiving $>1.5 \mathrm{~mL}$ NBCA. The study flow chart is shown in Figure 1. Patients were blinded to treatment allocation, significantly reducing the potential for bias and allowing a direct comparison of the outcomes of the two procedures. Repeated DUS was performed by a single surgeon immediately prior to the procedure using a Mindray M7 USG device (Mindray Bio-Medical Electronics Co. Ltd., Shenzhen, China). Patients were, then, transferred to the operating room.

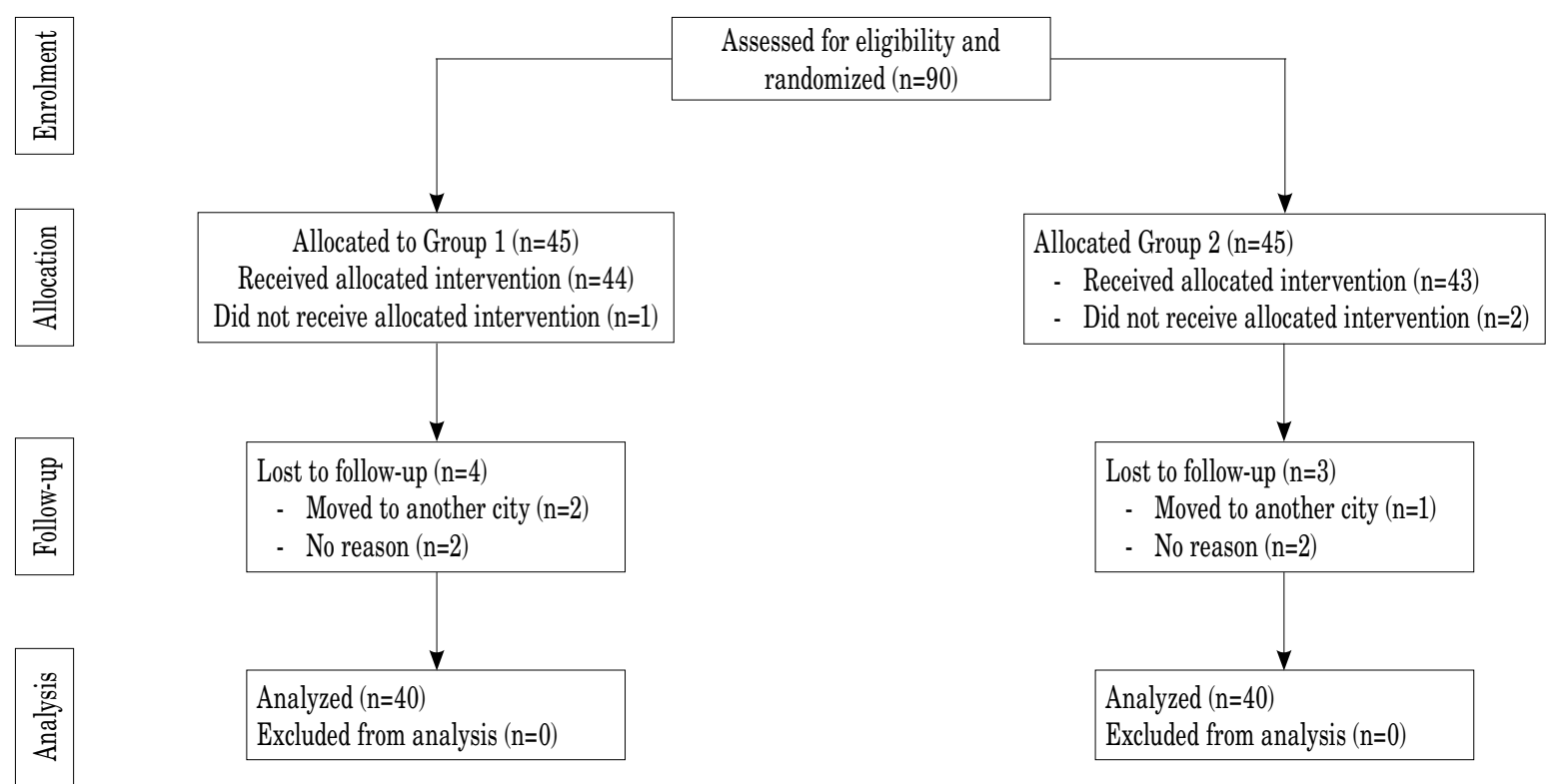

Figure 1. The CONSORT diagram of the study.

Group 1: $<1 \mathrm{~mL}$ N-butyl cyanoacrylate; Group 2: >1.5 mL N-butyl cyanoacrylate. 
The primary endpoint was the ablation rate. Secondary endpoints included the incidence of complications and patient satisfaction, as assessed by the following parameters: the absence of peri- and postoperative pain, and post-procedural complications. Data including age, sex, weight, and height were recorded preoperatively. The diameter, length and depth beneath the skin in the cannulation site of the target vein were recorded during surgery. Duration of procedure was also recorded. A Visual Analog Scale (VAS) was used to determine pain severity. The patients were asked to rate the pain experienced during the procedure on a scale from 0 to 10 , where 0 indicates no pain and 10 indicates the most extreme pain.

\section{Procedures}

All procedures were carried out under aseptic conditions in the operating room, with patients in the supine position. An ultrasound-guided 21-gauge needle was used for percutaneous puncturing of the saphenous vein. Cannulation was performed at the lowest point of reflux, followed by the insertion of a $6 \mathrm{~F}$ introducer sheath. No simultaneous phlebectomy was performed in any case.

Endovenous ablation was carried out using the VariClose ${ }^{\circledR}$ Vein Sealing System (Biolas, FG Grup, Ankara, Turkey). Briefly, a 0.035-inch, $150-\mathrm{cm}$ guidewire was introduced through the introducer sheath as far as the saphenofemoral junction (SFJ). The presence of the guidewire in the SFJ was first corroborated by DUS, after which a $5 \mathrm{~F}$ catheter was advanced to the SFJ over the guidewire. Once the position of the $5 \mathrm{~F}$ catheter at the beginning of the SFJ was confirmed, it was retracted by $6 \mathrm{~cm}$. This distance was employed, since the tip of the $4 \mathrm{~F}$ delivery catheter protrudes from the $5 \mathrm{~F}$ marker catheter by $3 \mathrm{~cm}$. We, therefore, positioned the $4 \mathrm{~F}$ delivery catheter $3 \mathrm{~cm}$ distal to the SFJ or SPJ. Confirmation of the location of the $4 \mathrm{~F}$ delivery catheter completed the NBCA injection groundwork. Next, $2 \mathrm{~mL}$ of NBCA was aspirated into the 2-mL injector. In Group 1, following catheter insertion, the vein was emptied by tapping before NBCA injection. Constant compression was applied before, during, and after injection (at a speed of $0.2 \mathrm{~mL} / \mathrm{sec}$, total $<1 \mathrm{~mL} \mathrm{NBCA}$ ). The procedure was, then, commenced. The standard procedure was performed in Group 2 (at a speed of $0.4 \mathrm{~mL} / \mathrm{sec}$; total $>1.5 \mathrm{~mL} \mathrm{NBCA}$ ). ${ }^{[8,9]}$ The time between the saphenous vein puncture and NBCA injection was recorded as the procedural time. Pressure on the vein continued to be applied for three min following the injection.
Whether the vein was occluded after the procedure was confirmed using DUS.

Once the procedure was completed, an elastic bandage was applied to the lower extremity involved and was removed after $24 \mathrm{~h}$. No restriction was placed on the patient activity, and all types of reasonable exercise were allowed from the first day of the procedure.

\section{Follow-up}

The patients were scheduled for follow-up including clinical and ultrasonographic examination on Day 3 and at one month postoperatively (at which blinding control was performed). Ultrasonography criteria for technical success were closed or absent GSV with the lack of flow. Recanalized GSV or treatment failure was defined as an open segment of the treated vein segment exceeding $5 \mathrm{~cm}$ in length. Post-procedural analgesia requirement, time to first analgesia requirement (in h), total number of use of $500 \mathrm{mg}$ paracetamol over three days among patients requiring analgesia, and pain perceptions at the end of Day 3 using the VAS scale were recorded. The Comprehensive Classification System for Chronic Venous Disorders (CEAP) and Venous Quality of Life (VQOL) scores at the first month were recorded and compared with the baseline scores.

\section{Primary and secondary outcomes}

Anatomical success defined as the closure and absence of reflux at color DUS analysis was adopted as the primary outcome. Secondary outcomes were subdivided into intra- and postoperative outcomes. Intraoperative outcomes included data concerning NBCA applied, duration of procedure, and concomitant phlebectomies, while postoperative outcomes included clinical and subjective success in the follow-up period, minor postoperative complications (i.e., pain, bruising, hematoma, burns, pigmentation, paresthesia, and superficial vein thrombosis [SVT]) and major postoperative complications (i.e., pulmonary embolism $[\mathrm{PE}]$ and deep venous thrombosis [DVT]).

\section{Statistical analysis}

Power analysis was performed to calculate the sample size. We planned to enrol 80 patients, 40 in each group, based on an $\alpha$ : 0.05 Type 1 error and $\beta$ : 0.20 Type 2 error level with 0.80 test power based on the parameters used in our reference studies. ${ }^{[17]}$

Statistical analysis was performed using the IBM SPSS version 22.0 software (IBM Corp., Armonk, NY, USA). Descriptive data were expressed in mean 
Table 1. Baseline demographic and clinical characteristics of the patients

\begin{tabular}{|c|c|c|c|c|c|c|c|}
\hline & \multicolumn{3}{|c|}{$1 \mathrm{~mL}$ or less } & \multicolumn{3}{|c|}{ More than $1 \mathrm{~mL}$} & \multirow[b]{2}{*}{$p$} \\
\hline & $\mathrm{n}$ & $\%$ & Mean $\pm S D$ & $\mathrm{n}$ & $\%$ & Mean $\pm S D$ & \\
\hline Age (year) & & & $49.4 \pm 12.7$ & & & $49.9 \pm 11.4$ & 0.846 \\
\hline Weight (kg) & & & $79.2 \pm 14.9$ & & & $84.8 \pm 13.5$ & 0.084 \\
\hline Height (cm) & & & $166.8 \pm 8.4$ & & & $164.9 \pm 9.8$ & 0.361 \\
\hline Body mass index $\left(\mathrm{kg} / \mathrm{m}^{2}\right)$ & & & $28.8 \pm 5.3$ & & & $31.1 \pm 5.4$ & 0.060 \\
\hline $\begin{array}{l}\text { Gender } \\
\text { Male } \\
\text { Female }\end{array}$ & $\begin{array}{l}17 \\
23\end{array}$ & & & $\begin{array}{l}13 \\
27\end{array}$ & & & 0.356 \\
\hline Diabetes mellitus & 8 & 20 & & 7 & 17.5 & & 1.000 \\
\hline Hypertension & 9 & 23 & & 11 & 27 & & 0.775 \\
\hline Hyperlipidemia & 1 & 2.5 & & 1 & 2.5 & & 0.651 \\
\hline Chronic obstructive pulmonary disease & 0 & 0 & & 1 & 2.5 & & 1.000 \\
\hline Smoking & 7 & 17.5 & & 10 & 25 & & 0.412 \\
\hline
\end{tabular}

SD: Standard deviation; Independent samples t-test; Chi-square test; Fisher's exact test; $\alpha: 0.05$.

\pm standard deviation (SD), median (interquartile range $[I Q R] 25^{\text {th }}-75^{\text {th }}$ ) or number and frequency. Normality of data distribution was examined using the Shapiro-Wilk test. Group comparisons of normally distributed variables were carried out using the independent samples t-test. Group comparisons of non-normally distributed variables were performed using the Mann-Whitney $U$ test. The chi-square and Fisher's exact tests were used to analyze significant differences between categorical variables. A $p$ value of $<0.05$ was considered statistically significant.

Table 2. Pre- and postoperative data

\begin{tabular}{|c|c|c|c|c|c|c|c|c|c|c|c|}
\hline & & & $1 \mathrm{~mL}$ and & & & & & $1 \mathrm{~mL}$ & & & \\
\hline & $\mathrm{n}$ & $\%$ & Mean \pm SD & Median & Q1-Q3 & $\mathrm{n}$ & $\%$ & Mean \pm SD & Median & Q1-Q3 & $p$ \\
\hline Amount of drug $(\mathrm{mL})$ & & & & 1.0 & $1.0-1.0$ & & & & 2.0 & $1.8-2.0$ & $0.001^{*}$ \\
\hline Preoperative vessel diameter (mm) & & & & 6.75 & $6.30-7.45$ & & & & 7.50 & $6.70-8.30$ & 0.098 \\
\hline Saphenous vein length $(\mathrm{cm})$ & & & & 33 & $31-35$ & & & & 34 & $32-35$ & 0.430 \\
\hline Duration of procedure (min) & & & & 5.0 & $4.0-6.0$ & & & & 6.0 & $5.5-8.0$ & $0.001^{*}$ \\
\hline Visual Analog Scale & & & & 0.0 & $0.0-1.5$ & & & & 1.0 & $0.0-2.0$ & $0.034^{*}$ \\
\hline Day 3 Visual Analog Scale & & & & 1.00 & $0.00-1.00$ & & & & 2.50 & $2.00-4.00$ & $0.001^{*}$ \\
\hline Use of analgesia & 17 & 42.5 & & & & 28 & 70 & & & & $0.013^{*}$ \\
\hline $\begin{array}{l}\text { Postoperative time to start of } \\
\text { analgesia use (hour) }\end{array}$ & & & & 18 & $6-24$ & & & & 4 & $3-6$ & $<0.001^{*}$ \\
\hline Number of analgesics (tablet) & & & & 2 & $2-4$ & & & & 6 & $4-8$ & $<0.001^{*}$ \\
\hline Phlebitis & 1 & 2.5 & & & & 3 & 7.5 & & & & 0.305 \\
\hline Ecchymosis & 2 & 5 & & & & 4 & 10 & & & & 0.396 \\
\hline $\mathrm{CEAP} \uparrow$ & & & & 3 & $2-3$ & & & & 3 & $2-3$ & 1.000 \\
\hline CEAP $1^{\text {st }}$ month $\dagger$ & & & & 2 & $2-3$ & & & & 2 & $2-3$ & 0.742 \\
\hline & & & $\mathrm{p}<0.00$ & & & & & $\mathrm{p}<0.00$ & & & \\
\hline $\mathrm{VQOL} \dagger$ & & & & 20 & $16.5-22$ & & & & 20 & $15.5-22$ & 0.811 \\
\hline VQOL 1.month $\dagger$ & & & $16.4 \pm 3.6$ & & & & & $16.7 \pm 4.1$ & & & \\
\hline & & & $p<0.00$ & & & & & $p<0.00$ & & & \\
\hline
\end{tabular}

CEAP: Comprehensive Classification System for Chronic Venous Disorders; Chi-square test; Mann-Whitney U test; Fisher's exact test; $\uparrow$ Mann-Whitney U test; Independent samples t-test; $\doteqdot$ Wilcoxon test; $\alpha: 0.05$; * Differences between groups statistically.significant. 


\section{RESULTS}

Ablation was successfully performed in 80 patients with GSV incompetence. Occlusion was observed in all patients in both groups at the postprocedural control USG, and no partial occlusion was detected in any case. Bilateral procedures were not performed in the same session in any case. All patients were symptomatic. The mean age was $49.3 \pm 12.6$ years in Group 1 and $49.8 \pm 11.4$ in Group 2 . The mean pre-procedural GSV diameters were 6.7 (range, 6.3 to 7.4 ) $\mathrm{mm}$ in Group 1 and 7.5 (range, 6.7 to 8.3$) \mathrm{mm}$ in Group 2, indicating no statistically significant difference. Baseline demographic and clinical characteristics of the patients are shown in Table 1.

The mean lengths of vein segments subjected to the NBCA application and ablation were

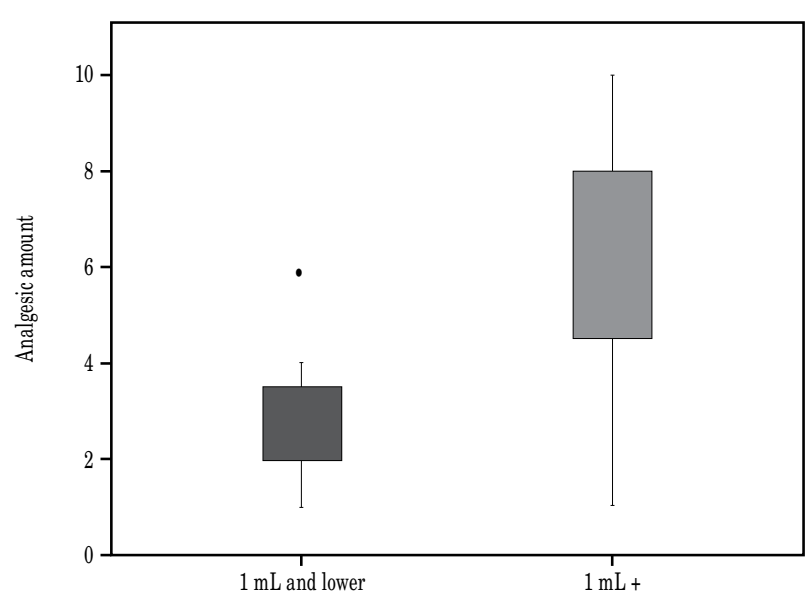

Figure 2. Amount of analgesia used.

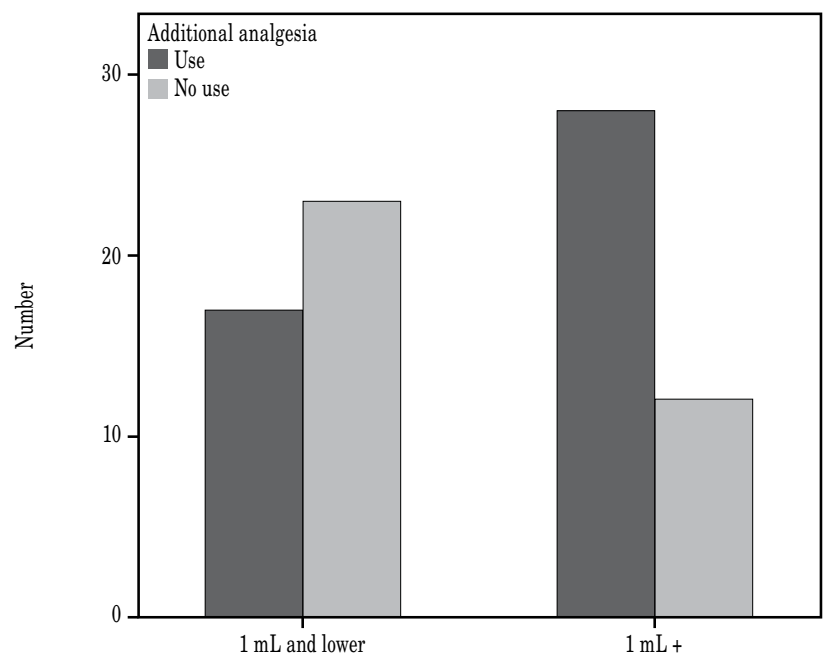

Figure 3. Rate of analgesic use.
33 (range, 31 to 35$) \mathrm{cm}$ in Group 1 and 34 (range, 32 to 35$) \mathrm{cm}$ in Group $2(\mathrm{p}=0.430)$. The mean procedural times were 5.0 (range, 4.0 to 6.0 ) $\mathrm{min}$ in Group 1 and 6.0 (range, 5.5 to 8.0) $\mathrm{min}$ in Group 2. A summary of the procedural characteristics is presented in Table 2. Fewer adverse events were found after $<1 \mathrm{~mL}$ NBCA administration compared to $>1.5$ $\mathrm{mL}$ NBCA administration, although it did not reach statistical significance (phlebitis, $p=0.305$, and ecchymosis, $\mathrm{p}=0.396$ ). However, statistically significant differences were observed between the two groups in terms of analgesia requirements, time to first analgesia requirement, and amounts of analgesic used, CEAP at one month, and VQOL at one month $(\mathrm{p}=0.013, \mathrm{p}<0.001, \mathrm{p}<0.001, \mathrm{p}<0.001$, and $\mathrm{p}<0.001$, respectively) (Figures 2 and 3, Table 2).

\section{DISCUSSION}

This study was designed based on the hypothesis that if the amount of NBCA administered inside the vessel was reduced, the severity of the inflammation which might develop would also decrease, in turn, resulting in improved patient comfort. Our study results showed that the same clinical success, with fewer complications (such as phlebitis, thrombophlebitis, ecchymosis, and pain) and greater patient comfort, can be achieved using a lower dose of NBCA in the treatment of venous insufficiency.

Endothermal treatment of the GSV has become the therapy of choice in superficial venous reflux. Endothermal ablation entails various advantages over open surgery, such as obviating the need for general anesthesia, a reduced operative time, and lower levels of postoperative pain and morbidity. ${ }^{[11]}$ However, one disadvantage of thermal endovenous ablation of truncal incompetence in cases of varicose veins is that tumescence anesthesia is required, a potential source of procedural discomfort, hematoma, and ecchymosis. Tumescent anesthesia is also a particularly difficult technique to master and extends the procedural time. ${ }^{[2]}$

The current NTNT methods are practical means of avoiding such complications during GSV and SSV ablation. ${ }^{[2]}$ One study reported a granulomatous foreign body reaction in the vein lumen 30 days following catheter-directed endovenous insertion of $\mathrm{N}$-butyl polymer into the superficial epigastric veins in a porcine model. ${ }^{[13]}$ Fibroblast invasion into the contents of the vein lumen and total occlusion were also observed 60 days post-procedurally in the same model. ${ }^{[14]}$ 
Polymerization time depends on the tissue type, the fluid characteristics, and the amount of product administered. Administered under appropriate conditions, NBCA polymerization commences within one to two sec and is completed in approximately five sec. Significant decreases in the procedural time, postoperative thrombophlebitis, and pain were observed in the present study due to the faster polymerization rate and lower viscosity of the NBCA polymer ( $\mathrm{p}=0.001, \mathrm{p}=0.002$, and $\mathrm{p}=0.001$, retrospectively). The mean procedural times in previous studies were 21 , 18.6, 24, and $13.3 \mathrm{~min}$, respectively. ${ }^{[15-18]}$ However, the duration of procedure requires more specific definition. The reported procedural time in a study was $5.4 \pm 2.5 \mathrm{~min},{ }^{[19]}$ indicating that some patients received NBCA treatment within $<3$ min. Our procedure resulted in a mean procedural time of five and six min for $<1 \mathrm{~mL}$ and $>1.5 \mathrm{~mL}$ administration, respectively, with a high total occlusion rate. Our relatively short procedural time may be due to the learning process having long since been completed, and to the widespread application of the technique in our routine practice.

The NBCA was first employed to treat GSV insufficiency in 2013 in a series of 38 patients. ${ }^{[20]}$ The mean treated vein length was $33.8 \mathrm{~cm}$. A complication rate of $21 \%$ was reported including phlebitis (15.8\%), cellulitis (4\%), hyperpigmentation in a vein located close to the skin (4\%), and thrombus extensions across the SFJ (21.1\%), although these all resolved completely during 12-month follow-up.

A multi-center, prospective European trial involving 70 patients was conducted using the VenaSeal $^{\mathrm{TM}}$ device. ${ }^{[16]}$ The mean GSV diameter in the SFJ was $7.8 \mathrm{~mm}$. Post-procedural complications included phlebitic reaction (11.4\%), pain (8.6\%) for a median one-day time frame, and adhesive extension beyond the SFJ (1.4\%). The rate of thrombophlebitis development in the present study was lower in Group 1 than in Group 2 (1:31, p=0.305). This is due to the absence of any cavity not filled with NBCA and of any residual blood in the vessel in the continuous technique. We attribute this to the lower viscosity of NBCA, the use of a smaller amount of NBCA, and the continuous compression employed in this study.

In their study, Almeida et al. ${ }^{[20]}$ reported mild pain and inflammation in as few as $13.2 \%$ of patients, that this was easily controlled by means of oral nonsteroidal anti-inflammatory drugs, and that all cases were self-limited. However, in the present study, analgesia requirement rates were higher, although none of our patients required oral non-steroidal anti-inflammatory drugs. Our patients used only paracetamol. Forty-two percent of the patients in Group 1 and $70 \%$ of those in Group 2 required analgesia. Pain, time to analgesia requirement (h), and amount of analgesia (tablet) used were significantly lower in the group receiving $<1 \mathrm{~mL}$ NBCA $(\mathrm{p}=0.013, \mathrm{p}<0.001$, and $\mathrm{p}<0.001$, respectively). A significant improvement was also observed in the CEAP and VQQ scores measured at the first month in both groups, compared to the baseline scores $(p<0.001$ for both). Furthermore, the lower development of thrombophlebitis and pain in this technique can be attributed to the absence of any empty spaces not containing glue and of any residual blood inside the vessel, and to the use of a lower amount of NBCA. In addition, continuous compression, rapid closure, and a very short procedural time have been shown to be capable of preventing DVT. Due to the rapid polymerization of NBCA, the SFJ section of the GSV was rapidly closed, and administration of optimal pressure over the SFJ lowered the risk of flow into the deep vein.

The small sample size and relatively short follow-up are the main limitations of the present study.

In conclusion, our study findings suggest that this novel NBCA technique is both safe and effective. We attribute our success rate in the $<1 \mathrm{~mL}$ group in particular to the polymerization rate, viscosity, and continuous compression which distinguishes our procedural technique from other methods. The technique allows rapid application with no open segments in the vein. We, therefore, believe that the same clinical success, with fewer complications (such as phlebitis, thrombophlebitis, ecchymosis, and pain) and greater patient comfort, can be achieved using a lower dose of NBCA in the treatment of venous insufficiency and the vast majority of incompetent GSV cases can be treated in this manner.

\section{Declaration of conflicting interests}

The authors declared no conflicts of interest with respect to the authorship and/or publication of this article.

\section{Funding}

The authors received no financial support for the research and/or authorship of this article.

\section{REFERENCES}

1. Lohr J, Kulwicki A. Radiofrequency ablation: evolution of a treatment. Semin Vasc Surg 2010;23:90-100. 
2. Bootun R, Lane TR, Davies AH. The advent of nonthermal, non-tumescent techniques for treatment of varicose veins. Phlebology 2016;31:5-14.

3. Levrier O, Mekkaoui C, Rolland PH, Murphy K, Cabrol $\mathrm{P}$, Moulin G, et al. Efficacy and low vascular toxicity of embolization with radical versus anionic polymerization of n-butyl-2-cyanoacrylate (NBCA). An experimental study in the swine. J Neuroradiol 2003;30:95-102.

4. Vinters HV, Galil KA, Lundie MJ, Kaufmann JC. The histotoxicity of cyanoacrylates. A selective review. Neuroradiology 1985;27:279-91.

5. Spiegel SM, Viñuela F, Goldwasser JM, Fox AJ, Pelz DM. Adjusting the polymerization time of isobutyl-2 cyanoacrylate. AJNR Am J Neuroradiol 1986;7:109-12.

6. McHugh SM, Leahy AL. What next after thermal ablation for varicose veins: non-thermal ablation? Surgeon 2014;12:237-8.

7. Almeida JI, Javier JJ, Mackay EG, Bautista C, Cher D, Proebstle TM. Three-Year Follow-Up of First Human Use of Cyanoacrylate Adhesive for Treatment of Saphenous Vein Incompetence. J Vasc Surg Venous Lymphat Disord 2015;3:125.

8. Eroglu E, Yasim A. A Randomised Clinical Trial Comparing N-Butyl Cyanoacrylate, Radiofrequency Ablation and Endovenous Laser Ablation for the Treatment of Superficial Venous Incompetence: Two Year Follow up Results. Eur J Vasc Endovasc Surg 2018;56:553-60.

9. Eroglu E, Yasim A, Ari M, Ekerbicer H, Kocarslan A, Kabalci M, et al. Mid-term results in the treatment of varicose veins with $\mathrm{N}$-butyl cyanoacrylate. Phlebology 2017;32:665-9.

10. Wittens C, Davies AH, Bækgaard N, Broholm R, Cavezzi A, Chastanet S, et al. Editor's Choice - Management of Chronic Venous Disease: Clinical Practice Guidelines of the European Society for Vascular Surgery (ESVS). Eur J Vasc Endovasc Surg 2015;49:678-737.

11. Marsden G, Perry M, Kelley K, Davies AH; Guideline
Development Group. Diagnosis and management of varicose veins in the legs: summary of NICE guidance. BMJ 2013;347:f4279.

12. Bozkurt AK, Y1lmaz MF. A prospective comparison of a new cyanoacrylate glue and laser ablation for the treatment of venous insufficiency. Phlebology 2016;31:106-13.

13. Min RJ, Almeida JI, McLean DJ, Madsen M, Raabe R. Novel vein closure procedure using a proprietary cyanoacrylate adhesive: 30-day swine model results. Phlebology 2012;27:398-403.

14. Almeida JI, Min RJ, Raabe R, McLean DJ, Madsen M. Cyanoacrylate adhesive for the closure of truncal veins: 60-day swine model results. Vasc Endovascular Surg 2011;45:631-5.

15. Almeida JI, Javier JJ, Mackay EG, Bautista C, Cher DJ, Proebstle TM. Two-year follow-up of first human use of cyanoacrylate adhesive for treatment of saphenous vein incompetence. Phlebology 2015;30:397-404.

16. Proebstle TM, Alm J, Dimitri S, Rasmussen L, Whiteley M, Lawson J, et al. The European multicenter cohort study on cyanoacrylate embolization of refluxing great saphenous veins. J Vasc Surg Venous Lymphat Disord 2015;3:2-7.

17. Morrison N, Gibson K, McEnroe S, Goldman M, King T, Weiss R, et al. Randomized trial comparing cyanoacrylate embolization and radiofrequency ablation for incompetent great saphenous veins (VeClose). J Vasc Surg 2015;61:985-94.

18. Şenol S, Türker FS, Temiztürk Z, Azboy D. Endovenous ablation technique using $\mathrm{N}$-butyl cyanoacrylate in varicose veins. Damar Cer Derg 2018;27:61-4.

19. Çalık ES, Arslan Ü, Ayaz F, Tort M, Yıldız Z, Aksu $\mathrm{V}$,et al. N-butyl cyanoacrylate in the treatment of venous insufficiency--the effect of embolisation with ablative polymerisation. Vasa 2016;45:241-6.

20. Almeida JI, Javier JJ, Mackay E, Bautista C, Proebstle TM. First human use of cyanoacrylate adhesive for treatment of saphenous vein incompetence. J Vasc Surg Venous Lymphat Disord 2013;1:174-80. 